\title{
Flexible and strong ternary blends of poly(vinyl chloride), poly(butylene adipate) and nanoparticle-plasticizers
}

\author{
Bo Yin, Minna Hakkarainen* \\ Department of Fibre and Polymer Technology, KTH Royal Institute of Technology, 10044 Stockholm, Sweden
}

\section{H I G H L I G H T S}

- Ternary blends of PVC, poly(butylene adipate) (PBA) and nanofillers were prepared.

- PBA plasticizer was grafted on surface of nanofillers.

- Simultaneous up to $100 \%$ increase in stress and strain at break was obtained.

\section{A R T I C L E I N F O}

\section{Article history:}

Received 6 August 2012

Received in revised form

15 December 2012

Accepted 3 February 2013

\section{Keywords:}

Polymers

Composite materials

Nanostructures

Mechanical properties

Ductility
G R A P H I C A L A B S T R A C T

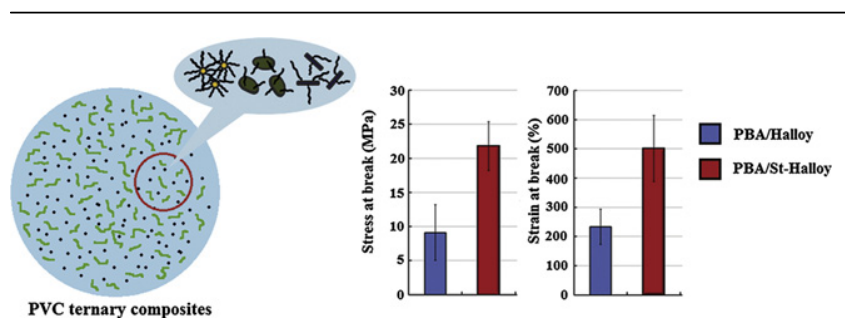

\begin{abstract}
A B S T R A C T
Multiple property enhancement was achieved for ternary blends of PVC, poly(butylene adipate) (PBA) plasticizer and PBA-grafted nanofillers as compared to ternary blends with untreated nanofillers. The blends with surface modified halloysite, kaolin or silicon dioxide nanofillers all exhibited higher stress at break and higher strain at break as compared to the corresponding composites with untreated nanoparticles. The strain at break was similar or improved compared to binary PVC/PBA blends. Most significant improvement was observed for the films containing surface treated halloysite nanofillers. Over $100 \%$ increase in stress at break and strain at break was obtained when compared to the corresponding nanocomposite containing untreated halloysite fillers. In addition to tensile testing the prepared films were characterized by DSC, SEM, TGA and FTIR imaging to evaluate the miscibility and thermal properties. Interestingly the FTIR imaging analysis revealed that the surface grafting of halloysite resulted not only in improved dispersion of halloysite filler, but also in more homogenous distribution of PBA plasticizer in the blends. During aging in contact with aqueous solution the films containing kaolin exhibited the smallest weight loss. This is explained by the plate like structure of kaolin which prevents the migration of PBA molecules.
\end{abstract}

(ㄷ) 2013 Elsevier B.V. All rights reserved.

\section{Introduction}

After the concept of polymer nanocomposites was introduced, PVC nanocomposites have attracted great interest. Multiple properties of polymer materials such as hardness, strength, fire retardancy, permeability and electricity properties can be tailored by blending different fillers, extending the application range of PVC

\footnotetext{
* Corresponding author. Tel.: +46 87908271.

E-mail address: minna@polymer.kth.se (M. Hakkarainen).
}

materials [1-3]. As an example electrical behavior of PVC was significant improved by addition of multiwalled carbon nanotubes [2]. PVC composites containing well-dispersed nanoclays exhibited increased material hardness and the smoke production was also significant decreased [3]. Some reduction in elongation of PVC materials is usually observed after blending with nanofillers, while hardness and strength of the materials are improved [4,5]. The aggregation of nanoparticles and weak interfacial adhesion may influence the mechanical properties of PVC negatively [6]. Some studies were carried out on surface-treatment of nanoparticles to improve the interfacial adhesion between nanoparticles and PVC 
matrix [7-9]. In one study layered double hydroxide particles were surface treated by toluene-2,4-di-isocyanate in toluene solution [10]. The surface treatment of nanoparticles significantly improved the thermal stability of the resulting PVC materials.

To produce flexible PVC materials with improved properties, ternary blends of PVC, nanoparticles and phthalate plasticizers have been prepared and evaluated [3,12-16]. Dioctyl phthalate (DOP) and organic clay were blended with PVC at different ratios [14]. The addition of small amount of DOP and clay slightly improved the mechanical properties of PVC materials. In another study di-isodecyl phthalate (DIDP) and hectorite or bentonite nanoclay as reinforcing filler was blended with PVC materials and the well dispersed nanoparticles in PVC/DIDP slightly enhanced the stiffness and decreased the smoke production of the materials [3]. The influence of dioctyl phthalate (DOP) plasticizer on the dispersion behavior of clay particles was also studied [15]. Certain amount of plasticizer improved the dispersion of clay in PVC, but increasing the amount of DOP had an adverse effect. Most of the investigations on plasticized PVC nanocomposites focused on the traditional phthalate plasticizers. Several phthalates have, however, already been partly phased out due to their negative impacts on health and environment $[17,18]$ and active research is going-on to replace phthalates with environmentally friendly alternatives including both monomeric $[19,20]$ and polymeric plasticizers, like poly (butylene adipate) (PBA) [21-24].

Recently we designed core-shell nanoparticle-plasticizers for PVC by grafting PBA chains on the surface of three different nanoparticles, kaolin, halloysite and silicon dioxide [11]. It was shown that the designed nanoparticle-plasticizers could simultaneously improve the stiffness and toughness of the PVC blends in comparison with the blends containing non-modified nanoparticles. The previous materials are still to be considered as hard PVC products as the amount of plasticizer grafted on the nanoparticle surface was rather low (2-30 wt\%) resulting in all cases less than $1.5 \mathrm{wt} \%$ of PBA in the films. Here we aimed at flexible PVC blends with retained or improved tensile strength and modulus.

\section{Materials and methods}

\subsection{Chemicals}

Halloysite nanoclay (Halloy), kaolin finest powder (Kaolin), silicon dioxide nanopowder $(5-15 \mathrm{~nm})\left(\mathrm{SiO}_{2}\right)$ were purchased from Sigma-Aldrich. The surface modification of the nanoparticles and their characterization [11] as well as synthesis and characterization of linear poly(butylene adipate) (PBA) (Mn $2400 \mathrm{~g} \mathrm{~mol}^{-1}$ PDI 2.0) [22] were reported in previous studies. The surface treated nanoparticles were denoted as St-Halloy (surface-treated halloysite nanoclay, 3 wt\% PBA grafted), St-Kaolin (surface-treated kaolin finest powder, 2 wt\% PBA grafted) and $\mathrm{St}-\mathrm{SiO}_{2}$ (surface-treated silicon dioxide nanopowder, $20 \mathrm{wt} \%$ PBA grafted). The percentage PBA grafted was determined by TGA [11]. Poly(vinyl chloride) (Mn $55,000 \mathrm{~g} \mathrm{~mol}^{-1}$ ) and tetrahydrofuran (THF, HPLC grade) were obtained from Fisher Scientific (UK Limited) and used without further purification.

\subsection{Preparation of PVC nanocomposite films}

Plasticized PVC films containing different nanoparticles were prepared by solution casting. $2 \mathrm{~g}$ mixture of nanoparticles (Kaolin, Halloy, $\mathrm{SiO}_{2}$, St-Kaolin, St-Halloy or St-SiO 2 ), free PBA and PVC powder were mixed in $80 \mathrm{ml} \mathrm{THF}$ ( $5 \mathrm{wt} \%$ nanoparticles, $40 \mathrm{wt} \% \mathrm{PBA}$, $55 \mathrm{wt} \% \mathrm{PVC}$ ) and stirred at $40^{\circ} \mathrm{C}$ for $2 \mathrm{~h}$, which was then followed by $2 \mathrm{~h}$ ultrasonication. The solutions were casted on clean petri dishes flushed with compressed air to minimize the presence of dust particles, dried in ambient pressure and room temperature for 7 days to evaporate the THF solvent. After that the solid films were put into vacuum oven for 7 days at room temperature packed in aluminum foils to evaporate the last traces of THF. After the preparation all the films were kept in desiccators for further testing. The thickness of dry films was approximately $70 \mu \mathrm{m}$. The films were named according to the plasticizer name and type of nanoparticle: PBA/Halloy, PBA/StHalloy, PBA/Kaolin, PBA/St-Kaolin, PBA/SiO 2 and PBA/St-SiO 2 .

\subsection{Tensile testing}

Tensile properties for all the films were determined by Instron 5566 equipped with pneumatic grips and Instron series IX software (Bristol, United Kingdom). The initial grip separation was $25 \mathrm{~mm}$;

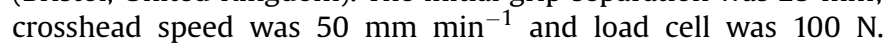
Elongation of testing specimens were calculated from grip separation by the software automatically. For each film, five specimens with a rectangular shape $\left(80 \times 5 \mathrm{~mm}^{2}\right)$ were prepared by using EP $04 / 80 \times 5 \mathrm{~mm}^{2}$ specimen cutter (Elastocon AB, Sweden). Before testing samples were conditioned in the same room as the instrument for six days at $23{ }^{\circ} \mathrm{C}$ and $50 \%$ humidity. The thicknesses of specimens were measured by digital thickness meter.

\subsection{Differential scanning calorimetry (DSC)}

DSC analysis of the blend films was performed on Metter-Toledo DSC 820 to determine the glass transition temperature and degree of crystallinity. Around $5 \mathrm{mg}$ of each sample was enclosed into standard $40 \mu \mathrm{L}$ aluminum cups. Temperature was raised $5^{\circ} \mathrm{C} \mathrm{min}{ }^{-1}$ from $25^{\circ} \mathrm{C}$ to $80^{\circ} \mathrm{C}$ and then decreased to $25^{\circ} \mathrm{C}$ with the same rate. After that the samples were cooled down from $25^{\circ} \mathrm{C}$ to $-50{ }^{\circ} \mathrm{C}$ at a rate of $1{ }^{\circ} \mathrm{C} \mathrm{min}^{-1}$, and $0.5^{\circ} \mathrm{C} \mathrm{min}^{-1}$ from $-50{ }^{\circ} \mathrm{C}$ to $-70{ }^{\circ} \mathrm{C}$. The temperature was kept constant at $-70{ }^{\circ} \mathrm{C}$ for $10 \mathrm{~min}$ and then increased from $-70^{\circ} \mathrm{C}$ to $120^{\circ} \mathrm{C}$ at a rate of $5^{\circ} \mathrm{C} \mathrm{min}^{-1}$. The whole temperature program was performed under a nitrogen gas flow of $80 \mathrm{ml} \mathrm{min}^{-1}$.

\subsection{Scanning electron microscopy (SEM)}

The Ultra-High Resolution FE-SEM (Hitachi S-4800) was used to get the topography information of the films and to evaluate influences of different nanoparticles on the miscibility and surface structure of the blends. Sample surfaces were treated by $2 \mathrm{~nm}$ thick carbon layer and $2 \mathrm{~nm}$ thick gold layers before analysis. Secondary electron detectors were used to record the SEM pictures for all the samples.

\subsection{Fourier transforms infrared spectroscopy (FTIR)}

FT-IR spectra and single-peak absorbance images of the nanocomposite films were recorded by using a Perkin-Elmer Spotlight 400 system equipped with optical microscope (Bucks, UK). Transmission mode was applied to obtain the images and the spectra. The obtained carbonyl peak absorbance images of the PVC nanocomposite films were used to evaluate the miscibility and distribution of PBA in the films.

\subsection{Thermogravimetric analysis (TGA)}

Mettler-Toledo TGA/SDTA 851e was used to evaluate the thermal stability of the samples. Around $10 \mathrm{mg}$ of each sample was put into a $100 \mu \mathrm{L}$ aluminum cup without lid. Samples were heated at $10{ }^{\circ} \mathrm{C} \mathrm{min}-1$ from $30{ }^{\circ} \mathrm{C}$ to $600{ }^{\circ} \mathrm{C}$ with $50 \mathrm{ml} \mathrm{min}^{-1}$ oxygen flow in the furnace. 


\subsection{Migration study}

$0.2 \mathrm{~g}$ film and $4 \mathrm{ml}$ distilled water were added into $20 \mathrm{ml}$ vial and sealed by metal led and kept 6 weeks at $25^{\circ} \mathrm{C}$. After 6 weeks of aging, all the samples were taken out from the water and weighted (wet weight), and then kept in vacuum oven until constant weight (dry weight). From these values water absorption and weight loss of the aged films were calculated according to equations below:

Weight $\operatorname{Loss}(\%)=\frac{\text { Original weight }- \text { Dry weight }}{\text { Original weight }}$

Water absorption(\%) $=\frac{\text { Wet weight }- \text { Dry weight }}{\text { Dry weight }}$

\section{Results and discussion}

Ternary blends of PVC, PBA and modified nanoparticleplasticizers were prepared with the aim to produce flexible films with retained or improved tensile strength and modulus. Ternary films with untreated nanoparticles were prepared for comparison to evaluate the effect of nanoparticle modification on the material properties. A schematic presentation of the modification of nanofillers is shown in Fig. 1.

\subsection{Mechanical properties of the PVC nanocomposite films}

Mechanical properties of the films were evaluated by tensiletesting measurements and the results are shown in Figs. 2-4. Fig. 2 shows that the surface treatment on nanoparticles generally slightly decreased the E-modulus of the composites. However, both $\mathrm{SiO}_{2}$ composites had significantly higher E-modulus in comparison with halloysite and kaolin composites and PVC/PBA reference blend. At the same time the composite containing surface modified $\mathrm{SiO}_{2}$ (PBA/St-SiO2) retained a similar strain at break value as the binary PVC/PBA blend. Generally the addition of untreated nanoparticles reduced the strain at break of the materials (Fig. 3), but after the surface treatment the strain at break values increased to similar or higher level in comparison with the binary PVC/PBA blend.

As seen from Figs. 3 and 4 all the films containing surface treated nanoparticles exhibited simultaneous improvement in stress and strain at break as compared to the films containing untreated nanoparticles. The most significant improvement of stress and strain at break was observed for PBA/St-Halloy films, which exhibited more than $100 \%$ increase of both stress at break and strain at break. This is deduced to the stronger interfacial adhesion between the nanoparticles and polymer matrix and more homogenous distribution of St-Halloy as compared to the Halloy nanoclay. The strain at break of the materials containing St-Halloy and St-Kaolin was slightly improved even in comparison with binary PVC/PBA blend. Pure PVC films had E-modulus $2556 \mathrm{MPa}$, strain at break $110 \%$ and stress at
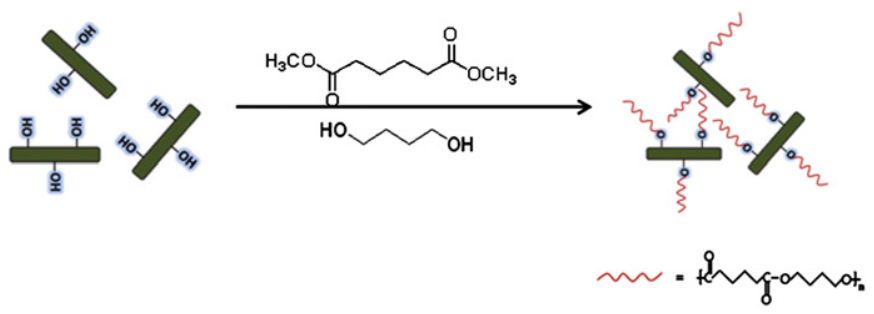

Fig. 1. Schematic presentation of nanoparticle surface treatment.

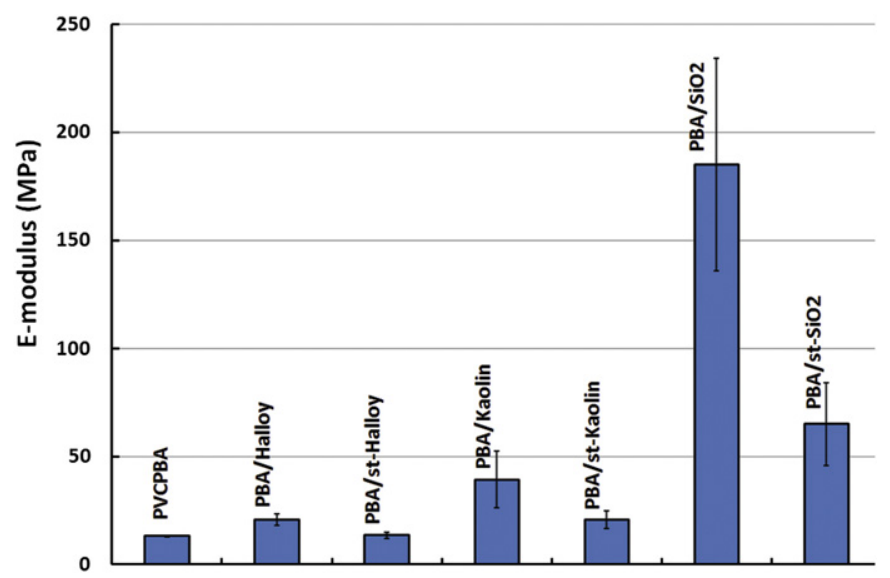

Fig. 2. E-modulus of the plasticized PVC nanocomposites.

break 46 MPa. Comparison with values presented in Figs. 2-4 show as a significant reduction in modulus and increase in strain at break for the plasticized films.

\subsection{Surface images and topography of the different PVC films}

The SEM pictures were taken from the top site of the films (the side in contact with air during solution casting) (Fig. 5). For the Halloy and Kaolin composites, the surfaces of the films containing modified fillers were more homogenous as compared to the films containing untreated fillers. Opposite to this the film containing surface treated $\mathrm{SiO}_{2}$ nanoparticles exhibited rougher surface than the one containing untreated $\mathrm{SiO}_{2}$ nanoparticles. The dispersion of nanoparticles in the matrixes was hard to observe due to the uneven surfaces topography. However, our previous study of binary PVC/nanoparticle films showed that the dispersion of nanoparticles in the PVC matrix was greatly improved by grafting of PBA [11].

\subsection{Distribution of PBA and nanoparticle-plasticizers in the films}

The distribution of PBA in the films was evaluated by singlepeak carbonyl absorbance images obtained from IR spotlight technique. Since the carbonyl groups only exist in PBA phase, lower carbonyl absorbance indicates lower than average PBA concentration at a certain point. The differences in carbonyl absorbance at different locations are indicated by colors and the images are shown in Fig. 6. The dark color in the image of PBA/Halloy (Fig. 6a)

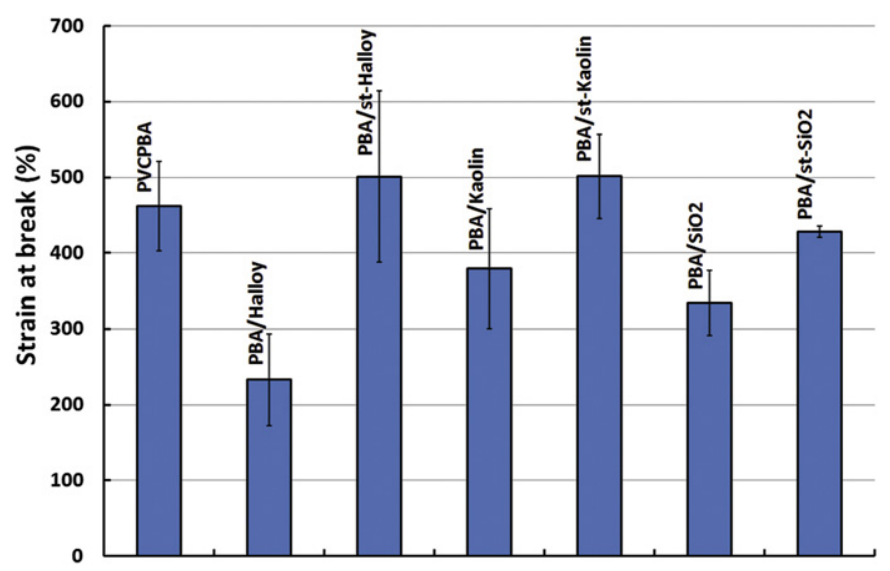

Fig. 3. Strain at break of the plasticized PVC nanocomposites. 


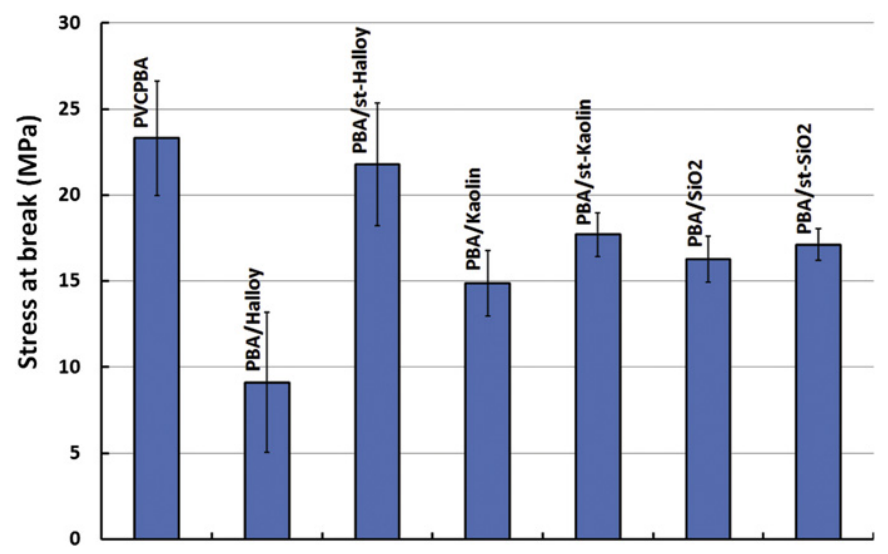

Fig. 4. Stress at break of the plasticized PVC nanocomposites.

indicates low concentration of PBA at corresponding area of the film. The PBA/Halloy films were by far the most heterogenous with respect to $P B A$ distribution, while the rest of the films appeared to have rather homogenous PBA distribution. Fig. $6 \mathrm{~b}$ reflects the clearly more homogenous nature of PBA/St-Halloy, which agrees with the greatly improved stress and strain at break after the surface treatment. Slightly brighter colors (yellow and red in web version) were observed locally in the images of PBA/Kaolin (Fig. 6c) and $\mathrm{PBA} / \mathrm{St}-\mathrm{SiO}_{2}$ (Fig. 6f) in comparison with PBA/St-Kaolin (Fig. 6d) and $\mathrm{PBA} / \mathrm{SiO}_{2}$ (Fig. 6e). This indicates spots with higher PBA concentration in $\mathrm{PBA} / \mathrm{Kaolin}$ and $\mathrm{PBA} / \mathrm{St}-\mathrm{SiO}_{2}$ probably due to local PBA crystallization, which correlates well with the degree of crystallinity measurements.

\subsection{Glass transition temperature and degree of crystallinity}

Glass transition $\left(T_{g}\right)$ temperatures and regions (Table 1 ) as well as degree of crystallinity (Fig. 7) for the films were determined by DSC. No great differences were observed in the $T_{g}$ 's of the films containing treated nanoparticles and corresponding untreated nanoparticles. However, for the films containing surface treated nanoparticles the glass transition started at a slightly higher temperature and the $T_{g}$ region was somewhat narrower, which could be explained by higher homogeneity of the films including better dispersion of nanoparticles. Better dispersion of nanoparticles in the polymer matrix could also restrict the movement of polymer
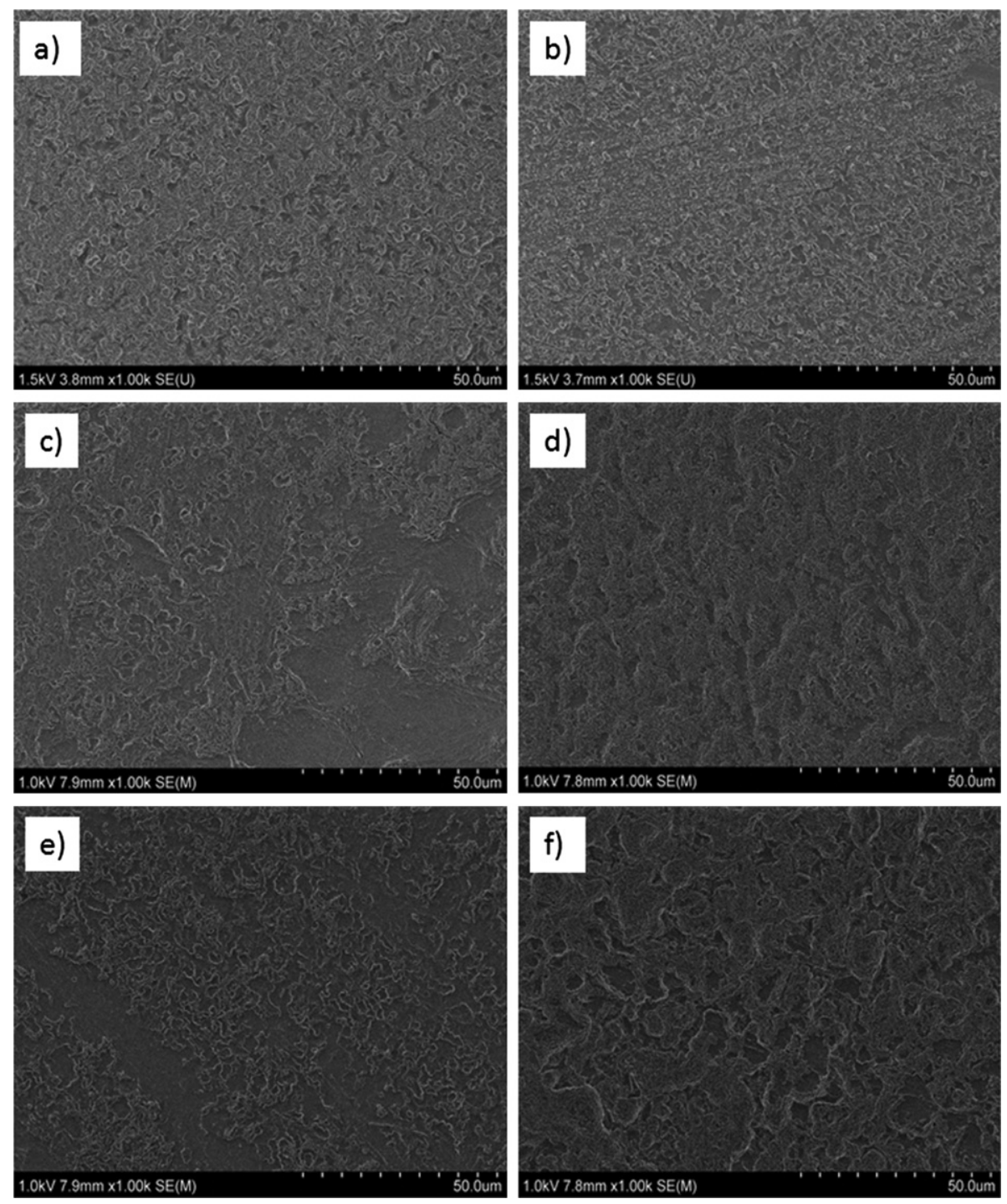

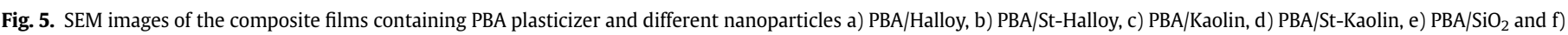
$\mathrm{PBA} / \mathrm{St}-\mathrm{SiO}_{2}$. 

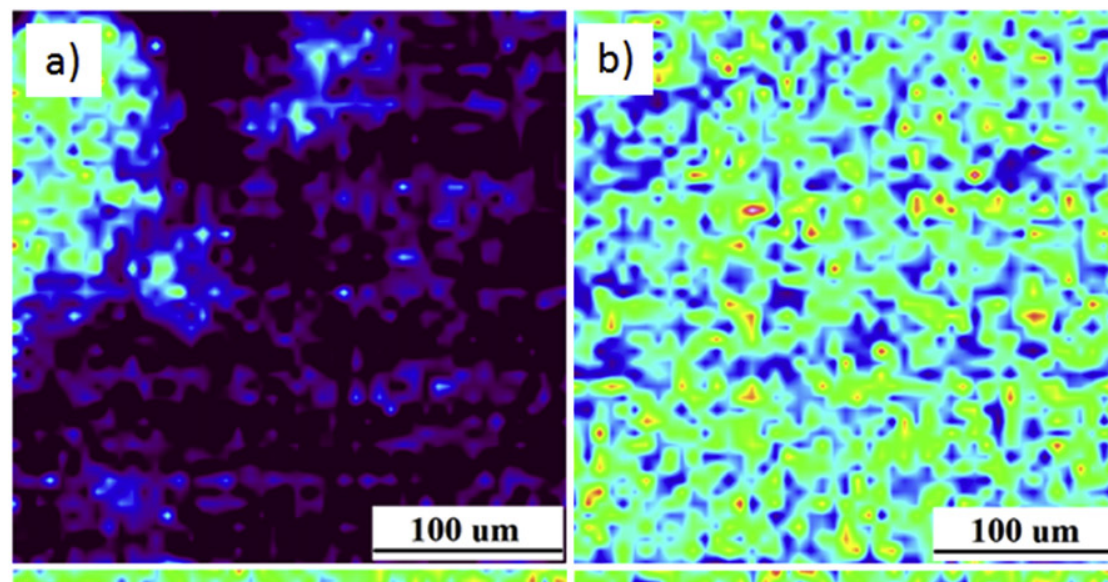

\section{Abs \\ 3.209 \\ 3.115 \\ 3.024}
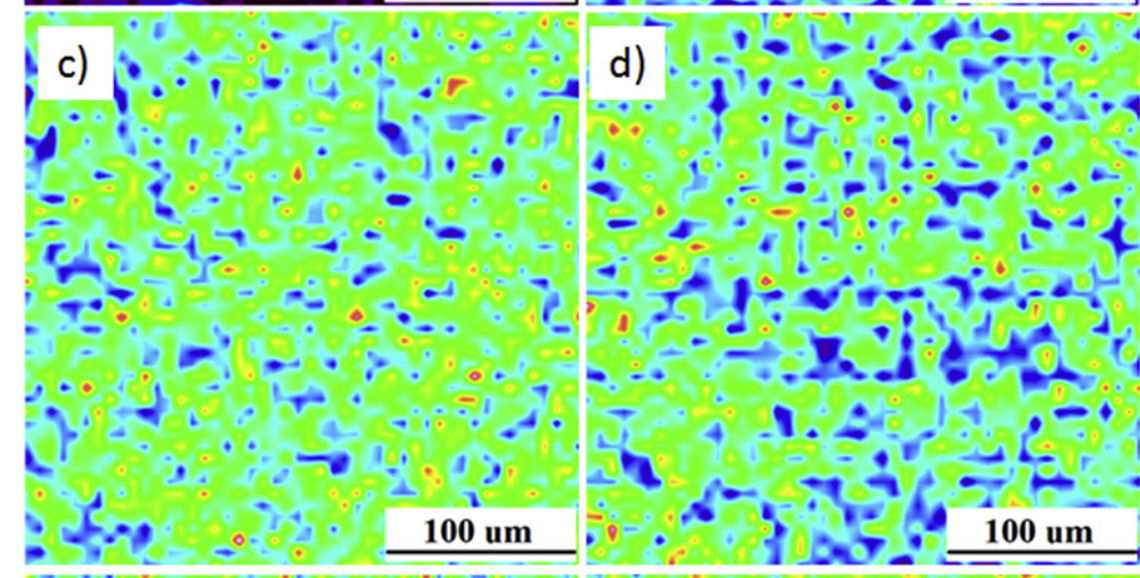

2.934
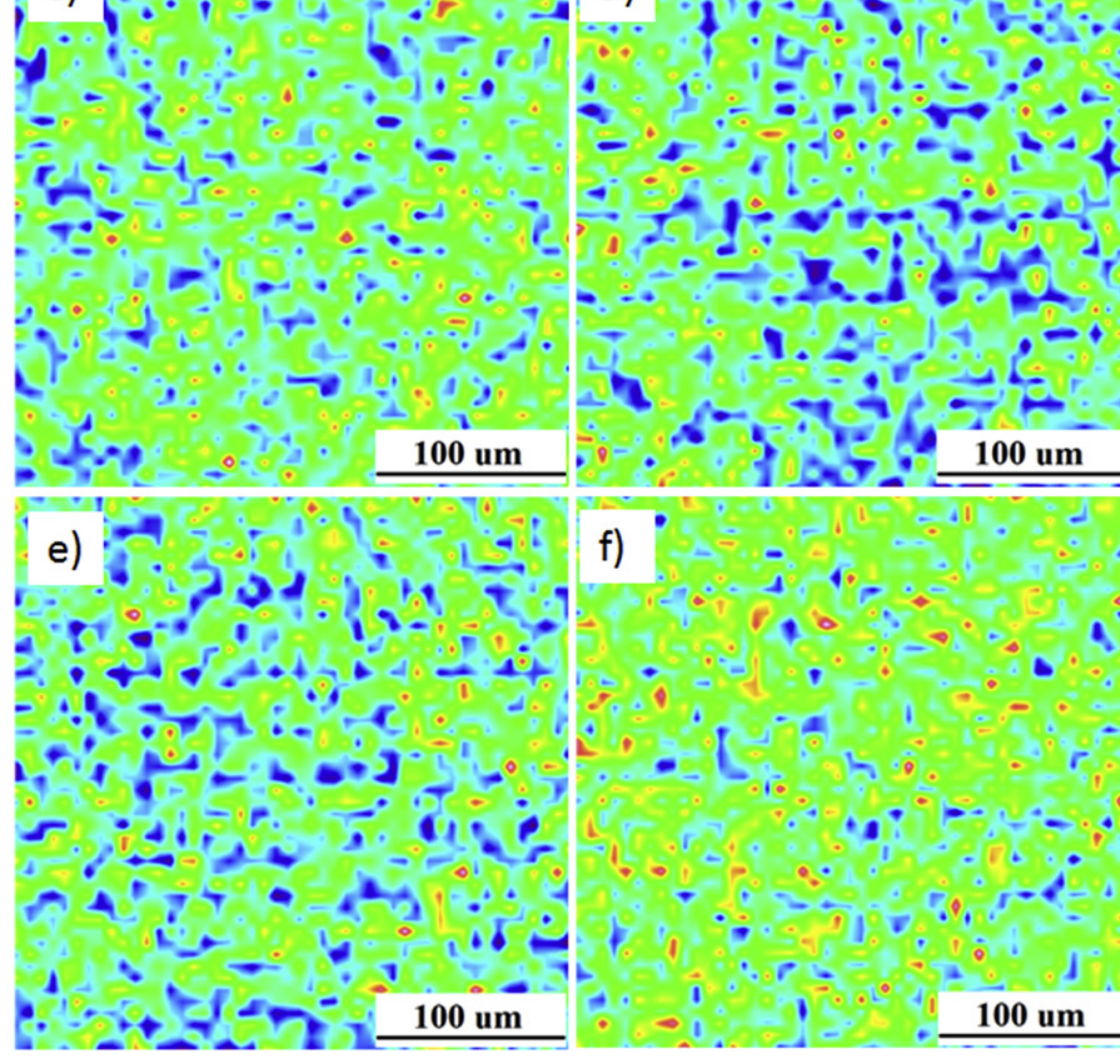

2.843

2.757

2.662

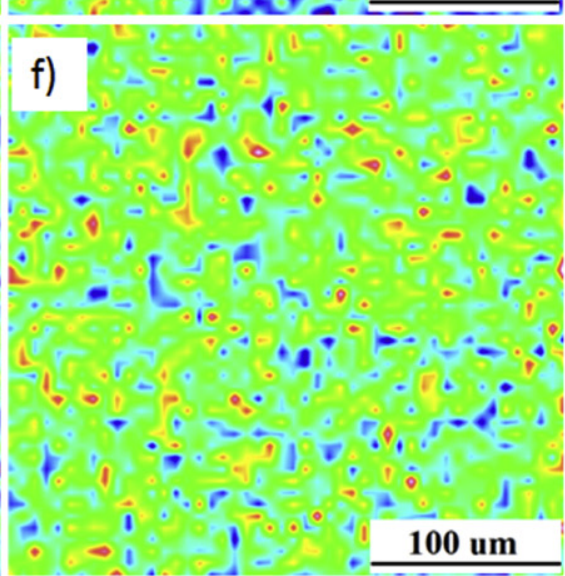

2.572

2.481

2.391

Fig. 6. Carbonyl signal-peak absorbance images of the composite films containing PBA plasticizer and different nanoparticles a) PBA/Halloy, b) PBA/St-Halloy, c) PBA/Kaolin, d) PBA/ St-Kaolin, e) $\mathrm{PBA} / \mathrm{SiO}_{2}$ and f) $\mathrm{PBA} / \mathrm{St}_{-}-\mathrm{SiO}_{2}$.

Table 1

Glass transition temperatures of the PVC films.

\begin{tabular}{lcl}
\hline Material & $T_{g}\left({ }^{\circ} \mathrm{C}\right)$ & $T_{g}$ range $\left({ }^{\circ} \mathrm{C}\right)$ \\
\hline PVC & 56 & 48 to 65 \\
PVC/PBA & -13 & -27 to -1 \\
PVC/PBA/Halloy & -19 & -36 to -2 \\
PVC/PBA/St-Halloy & -18 & -32 to -4 \\
PVC/PBA/Kaolin & -17 & -35 to -1 \\
PVC/PBA/St-kaolin & -17 & -35 to -2 \\
PVC/PBA/SiO & -16 & -30 to 1 \\
PVC/PBA/St-SiO & -15 & -26 to -1 \\
\hline
\end{tabular}

chain segments resulting in higher glass transition temperatures. This could explain the small differences observed between the different nanoparticles.

Some crystallization of PBA plasticizer took place in most of the composite films (see Fig. 7). However, the degree of crystallinity was in all cases quite low especially for the halloysite and kaolin composites. For PBA/Halloy and PBA/kaolin nanocomposites, the crystallinity was lower for the films containing surface treated nanoparticles as compared to the ones containing untreated particles. This could indicate that the untreated nanoparticles functioned as nucleation points for PBA crystallization. However, PBA/ $\mathrm{St}-\mathrm{SiO}_{2}$ nanocomposites exhibited higher crystallinity as compared to the $\mathrm{PBA} / \mathrm{SiO}_{2}$. This is explained by the higher PBA content on the surface of $\mathrm{SiO}_{2}$ as compared to surface treated Halloy and Kaolin as 


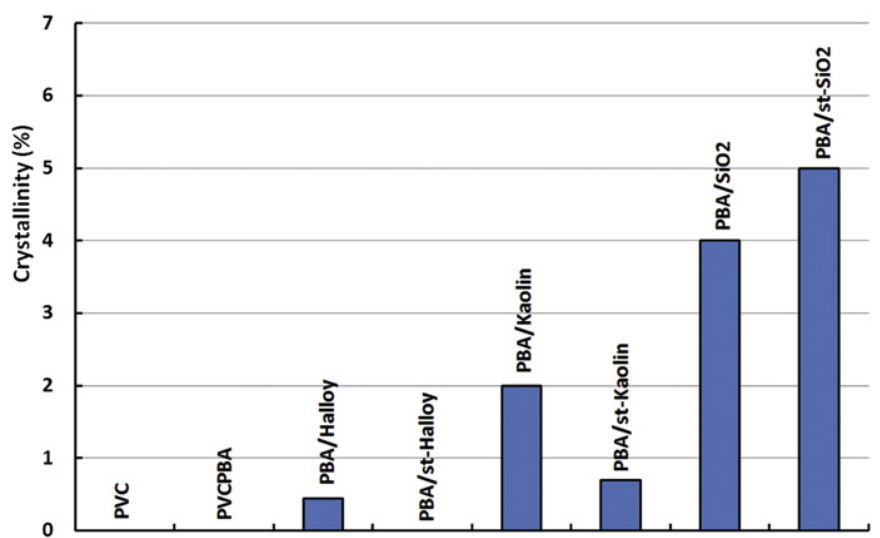

Fig. 7. Degrees of crystallinity for the PVC nanocomposite films.

well as the agglomeration of untreated $\mathrm{SiO}_{2}$. These results correlate well with the SEM images, which showed higher surface roughness for $\mathrm{PBA} / \mathrm{St}-\mathrm{SiO}_{2}$ as compared to $\mathrm{PBA} / \mathrm{SiO}_{2}$.

\subsection{Thermal stability}

Thermal stability of the PVC nanocomposite films and the effect of different fillers were evaluated by TGA (Fig. 8). No great differences were observed between the films, but the onset of degradation for halloysite composites was slightly lower as compared to the $\mathrm{SiO}_{2}$ and kaolin composites. In all cases the degradation started at around $250{ }^{\circ} \mathrm{C}$. Enlargements of the curves in the temperature
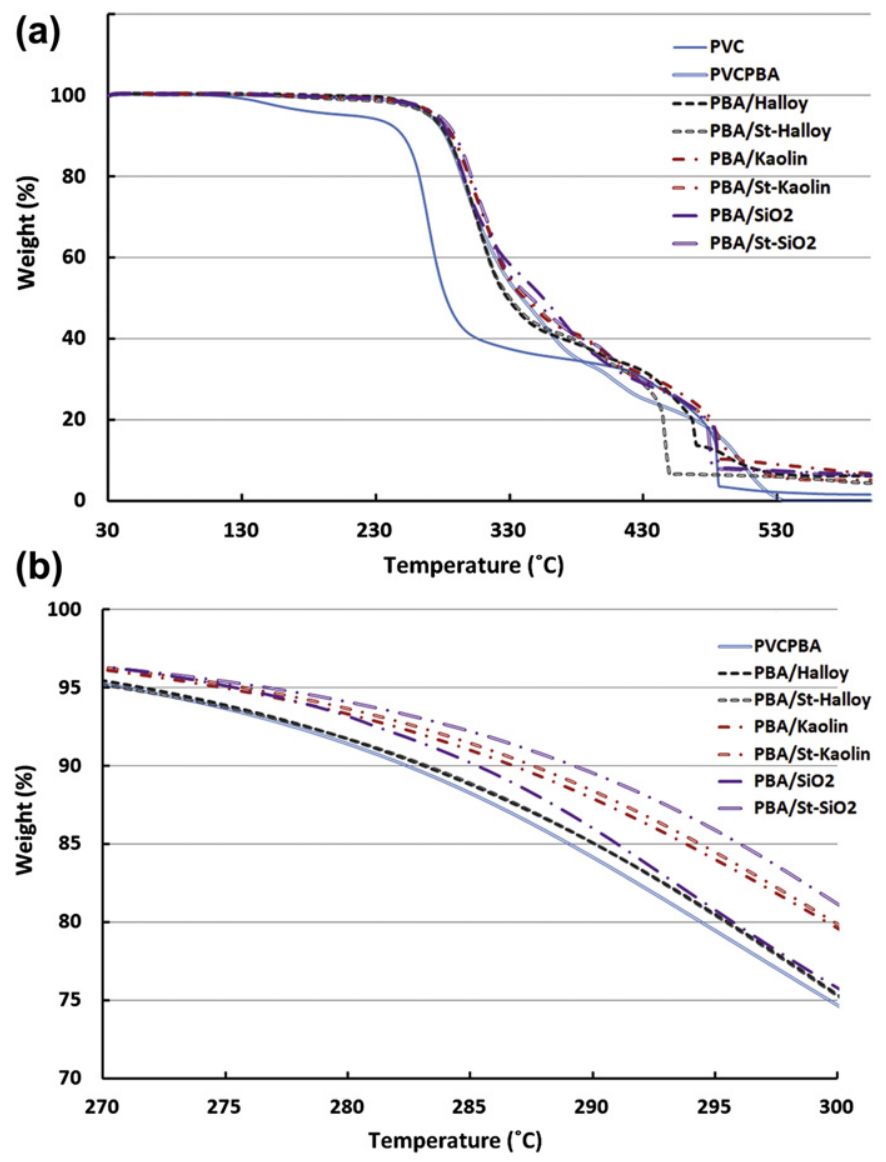

Fig. 8. TGA curves showing the remaining sample weight as a function of temperature for the different nanocomposite films.

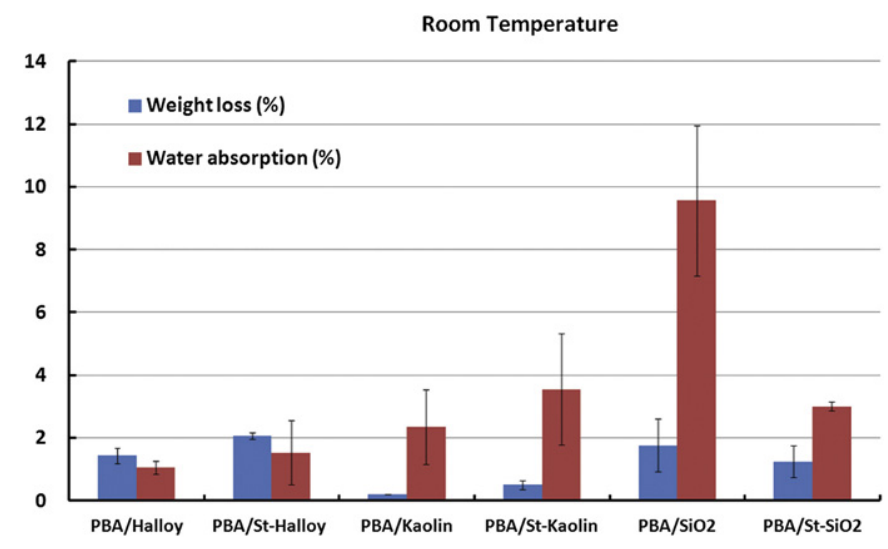

Fig. 9. Weight loss and water absorption of the nanocomposites.

range from $270{ }^{\circ} \mathrm{C}$ to $300^{\circ} \mathrm{C}$ (Fig. 8b), show that the films containing surface treated $\mathrm{SiO}_{2}$ nanoparticles exhibited slightly better stability than the ones containing untreated nanoparticles. The surface treatment of kaolin and halloysite nanoparticles did not significantly influence the thermal stability.

\subsection{Migration behavior}

PBA plasticizer can degrade and migrate from PVC during prolonged contact with aqueous solutions [23]. To determine the influence of nanoparticles on the migration behavior of PBA, nanocomposites containing surface treated or untreated nanoparticles were aged in distilled water at room temperature. The influence of the nanoparticles on the water uptake and on the migration behavior was evaluated and the results are shown in Fig. 9. The films containing surface treated halloysite and kaolin nanoparticles exhibited slightly higher water uptake and higher weight loss than films containing untreated particles. The films containing untreated $\mathrm{SiO}_{2}$ showed similar weight loss but much higher water absorption as compared to the films containing surface treated $\mathrm{SiO}_{2}$. This is explained by the higher hydrophilicity of the untreated $\mathrm{SiO}_{2}$ nanoparticles in combination with aggregation and poor compatibility with PVC matrix enabling the migration of water into the material [11]. Generally the weight loss of kaolin nanocomposites was smaller as compared to the weight loss of halloysite and $\mathrm{SiO}_{2}$ nanocomposites. This is explained by the layered structure of kaolin particles making it more difficult for the PBA molecules to migrate from the material.

\section{Conclusion}

Several material properties could be improved by PBA-grafting of nanofillers in ternary blends of PVC, PBA and nanofillers. The blends with surface modified halloysite, kaolin or silicon dioxide nanofillers all exhibited higher stress at break and higher strain at break as compared to the corresponding composites with untreated nanoparticles. Most significant difference was observed for the films containing surface treated halloysite nanofillers. The stress at break and strain at break both increased with more than $100 \%$ as compared with the corresponding nanocomposites containing untreated halloysite fillers. Plate like structure of kaolin led to more migration resistant materials. 


\section{Acknowledgments}

The authors gratefully acknowledge the financial support from the Swedish Research Council (contract grant number 2007-5542).

\section{References}

[1] T. Uma, T. Mahalingam, U. Stimming, Mater. Chem. Phys. 90 (2005) 239-244.

[2] Y.P. Mamunya, V.V. Levchenko, A. Rybak, G. Boiteux, E.V. Lebedev, J. Ulanski, G. Seytre, J. Non-Cryst. Solids 356 (2010) 635-641.

[3] W.H. Awad, G. Beyer, D. Benderly, W.L. Ijdo, P. Songtipya, M.d.M. JimenezGasco, E. Manias, C.A. Wilkie, Polymer 50 (2009) 1857-1867.

[4] I. Kemal, A. Whittle, R. Burford, T. Vodenitcharova, M. Hoffman, Polymer 50 (2009) 4066-4079.

[5] Z.-M. Liang, C.-Y. Wan, Y. Zhang, P. Wei, J. Yin, J. Appl. Polym. Sci. 92 (2004) $567-575$.

[6] J. Pagacz, K. Pielichowski, J. Vinyl Addit. Technol. 15 (2009) 61-76.

[7] L. Yang, Y. Hu, H. Guo, L. Song, Z. Chen, W. Fan, J. Appl. Polym. Sci. 102 (2006) 2560-2567.

[8] A. Zhu, A. Cai, J. Zhang, H. Jia, J. Wang, J. Appl. Polym. Sci. 108 (2008) 2189-2196.
[9] K. Hayashida, H. Tanaka, O. Watanabe, Polymer 50 (2009) 6228-6234.

[10] J. Liu, G. Chen, J. Yang, L. Ding, Mater. Chem. Phys. 118 (2009) 405-409.

[11] B. Yin, M. Hakkarainen, J. Mater. Chem. 21 (2011) 8670-8677.

[12] L. Kovarova, A. Kalendova, J.-F. Gerard, J. Malac, J. Simonik, Z. Weiss, Macromol. Symp. 221 (2005) 105-114.

[13] T. Peprnicek, A. Kalendova, E. Pavlova, J. Simonik, J. Duchet, J.F. Gerard, Polym. Degrad. Stab 91 (2006) 3322-3329.

[14] D. Wang, D. Parlow, Q. Yao, C.A. Wilkie, J. Vinyl Addit. Technol. 7 (2001) 203-213.

[15] B. Yalcin, M. Cakmak, Polymer 45 (2004) 6623-6638.

[16] X. Zheng, M. Gilbert, J. Vinyl Addit. Technol. 17 (2011) 231-238.

[17] R. Stringer, I. Labunska, D. Santillo, P. Johnston, J. Siddorn, A. Stephenson, Environ. Sci. Pollut. Res. 7 (2000) 27-36.

[18] J.A. Tickner, T. Schettler, T. Guidotti, M. McCally, M. Rossi, Am. J. Ind. Med. 39 (2001) 100-111.

[19] B. Yin, M. Hakkarainen, J. Appl. Polym. Sci. 119 (2011) 2400-2407.

[20] M. Rahman, C.S. Brazel, Prog. Polym. Sci. 29 (2004) 1223-1248.

[21] A. Lindström, M. Hakkarainen, J. Appl. Polym. Sci. 100 (2006) 2180-2188.

[22] A. Lindström, M. Hakkarainen, J. Polym. Sci. Polym. Phys. 45 (2007) 1552-1563.

[23] A. Lindström, M. Hakkarainen, J. Appl. Polym. Sci. 104 (2007) 2458-2467.

[24] A. Lindström, M. Hakkarainen, Biomacromolecules 8 (2007) 1187-1194. 